\title{
The Role of e-Learning Materials in Enhancing Teaching and Learning Behaviors
}

\author{
A. Alenezi
}

\begin{abstract}
Education is a critical right, and a significant input within any country. Its importance to the economy of a country has resulted in significant investments into the education sector across the world, especially in Saudi Arabia. Due to the increasing integration of the internet into the everyday lives of individuals, e-learning has become a fundamental tool within the education sector. This study assesses how the existence and use of e-learning materials within educational environments affects the teaching and learning behaviors of teachers and students respectively. Based on this analysis, the study found that the greater the use of e-learning materials and tools within an educational context, the higher the performance of the students and the efficiency of teaching practices.
\end{abstract}

Index Terms - Conventional learning, Internet, e-learning, digital learning.

\section{Purpose and Rationale}

Education is a critical aspect of sustainable development. The significance of education especially in developed nations has increased due to the rising nature of global competitiveness. Each year, more individuals become connected to the network, making it more integrated within all the happenings in the world. There are already several e-learning programs provided in different countries. Many learning approaches already in existence in Saudi Arabia, for example, the existence of the National Education Portal (iEN) from which students and learners can access an extensive library of learning and teaching resources [1]. E-Learning refers the utilization of ICT by tutors and students as it involves traditional practices such as courses and formalization through the collection of documents.

E-learning may be described as a learning procedure whose creation is through interactions with the digital delivery of content, services based on the network and support from tutors [2]. It is a shift from conventional education to collaborative learning founded on ICT channels and characterized by personalization, self-organization, and flexibility. It is the utilization of an internet technology for the enhancement of knowledge and performance. Learners gain the capability of controlling the content, learning processes and the speed at which learning occurs while also enabling them to customize the experience that they have for the achievement of their goals [3]. This has made it highly popular within most tutors and learners. The creation of e-learning includes various components- after the development of content, it has to undergo management,

Manuscript received August 3, 2019; revised November 20, 2019.

Abdullah Alenezi is with Northern Border University, Saudi Arabia (e-mail: Abdullah.a.alenezi@nbu.edu.sa). delivery, and standardization. Content includes all instruction materials which may differ in how complicated they are from discrete features to extended instruction manuals. Digital learning materials can undergo definition as a group of digital features designed appropriately and linked to education-based goals. Learning factors are a representation of discrete units of instructional materials structured on the basis of a particular learning goal which is utilized for the creation of grater education material such as a lesson designed to meet the requirement of a specific curriculum [4]. Some applications of e-learning channels include portals, digital libraries, or even an e-portfolio.

The significance of education is increasing due to an elevation of the need to be at par with rest of the world in regards to internal competition. The Saudi Arabian education system has experienced great growth with only one objective-to make sure that the efficiency of education increases to meet religious, economic and social needs of the country as well as to drive the eradication of illiteracy among Saudi youth and adults. SA is one of the highest spenders in the world within the education sector which receives a large share of the budget at almost a quarter of the total spending. Based on a mission statement from the Saudi Arabian Ministry of Higher Education, e-learning is not just an aspect added for the facilitation and acceleration of the existing traditional education, it is an evolving environment whose integration with different elements of the educational process, is to enable the internal enrichment of the educational system. The education system in Saudi Arabia has an increasing demand for the provision of additional educational opportunities, as the population increases. This has necessitated a national plan for the adoption of information technology across the country.

There are several reasons for the rapid growth of e-learning in Saudi Arabia. One of these reasons is that the demand for education far outweighs the supply with many educational institutions having to deal with overcrowding and insufficient facilities for the delivery of the traditional style of education. E-learning acts as an appropriate style for overcoming thesechallenges. Another factor is that the Kingdom is a large country in terms of geographical space, which results in the isolation of a large number of communities. E-learning provides the potential for delivering educational services to a remote location, hence decreasing disparities within different regions and areas. Lastly, within the kingdom, men and women usually receive their instructions in different classes, due to the country's culture and religion [5]. This increases the level of strain placed on the limited facilities and human resources available. Women have also been identified as being stronger supporters of 
e-learning in comparison to the male population, as it facilitates their access to education.

Most decision-makers link e-learning to new learning practices which that have higher cost efficiency in comparison to conventional learning strategies which enables learners to customize their own learning experiences while teachers get the opportunity to more effectively structure their teaching practices. This has largely changed the way information is handled and managed within academic environments. Several learning initiatives have been structured to help in the developing students as well as electronic materials in several learning facilities. Despite these efforts, several shortcoming in developing, providing and utilizing electronic materials have been acknowledged across learning institutions in the kingdom. As the utilization of e-learning has become more popular in academic institutions, it has become more significant to the examination of the effect that this has on teaching styles and the performance of students.

This study is marginally significant. The results of the research provides ideas concerning e-learning features and the academic achievement for the provision of critical data to increase studies work in these sectors. It also provides the necessary knowledge and guidelines that concerned policymakers may take advantage of. Lastly, this paper highlights inputs to the learners, researchers, and teachers as concerns e-learning.

\section{RESEARCH QUESTIONS AND OBJECTIVES}

\section{A. Research Questions}

The research questions below were utilized to guide data collection while also structuring the research instruments used;

- Do computer skills affect the level at which e-learning used to enhance teaching and learning behaviors?

- At what level do social and demographic factor affect the learning and teaching behaviors of students and tutors?

- Does engagement of e-learning materials have an effect in academic performance?

\section{B. General Objectives}

The general objective of this research was establishing the impact that e-learning has on teaching and learning behaviors.

\section{Specific Objectives}

- To determine the roles that computer competency may have on learning practices in students.

- To establish the effect of the duration spent offline/online on the academic performance of students.

- To determine the impact of using e-learning strategies on the efficiency of teaching practices

\section{LITERATURE REVIEW}

\section{A. The Role of e-Learning on Academic Performance}

There are varying attitudes in regards to e-learning. With some researchers, e-learning has been believed to have the same level of effectiveness as traditional methods of educational instructions, and that there is no large distinction which exists in academic performance between traditional and internet-based modes teaching by tutors. However, many reviews make a reflection of largely positive attitudes concerning the effect of e-learning on teaching practices. A wide range of works of literature which indicated that varying teaching delivery styles have various levels of efficiency- with the main measurement being the level of academic success [6]. With teaching using e-strategies, various studies state that this channel of delivery has a positive effect on how students perform, while other studies stating that it instead has an adverse effect.

Benefits involve several new opportunities for students, while also having a positive impact on what the students achieve in various educational factors. Some advantages of e-learning involve an enhancement of the numbers of individuals enrolled in school and the time they spend on educational programs are able to access to separated regions, wider education opportunities for learners who cannot access the traditional education institutions, an increase to access of resources and instructors who cannot be locally consulted, and an improvement in the communication between students and teachers [3]. Students within virtual learning display a higher level of improvement as compared to those within purely traditional school systems in areas such as critical thinking. The use of computers and independent learning. A study indicated that learning benefits over conventional schools were displayed by students in Mexico's Telesecenduria program, as they were more likely to pass the final examination provided by the state, by the student taking a chemistry by satellite course and by students who learned reading and math through interactive radio interactions [7].

E-learning is not the best application in each situation. The learners involved can be exposed to negative environments with factors such as isolation, language difficulties, and lack of practicality in areas such as foreign language teaching. Parents may also be worried in regards to the social development of the student. The greater the increased distance between tutors and learners while incorporating e-learning programs for teaching and learning, the greater the adverse impact on how they perform, how students are engaged, and the refining of skills and knowledge. Subjects with high technicalities, such as mathematics and sciences, are also challenging to teach through online methods. Due to the instruction of equal quality, students who learn through e-learning program, usually have achievements that are almost as equal to those in purely traditional classrooms [4]. Equal levels within the delivery systems have been observed over the years for adult learners. When utilized appropriately, electronically delivered learning. E-learning can increase the quality of learning of the learners and results in an improvement of what the students learn. However, students who use pre-dominantly e-learning techniques in their learning practices have several advantages to those within purely traditional systems which include an increase in the level of autonomy and responsibility. They also possess an internal factor of motivation which increases their 
persistence in education activities.

\section{B. The Impact of Computer Skills}

When it comes to e-learning technologies, some learners usually have an upper hand as compared to others for the facilitation of education programs. This individual advantage is usually significant in deciding the success of applying e-learning to education. Experiences that learners and teachers have with internet technologies is identified as the level of competency that students have with computers while being common with individuals that have high levels of income. There is a great difference between learners that are largely skilled in using computer tools as compared to those that have not yet had a chance to engage in the development of their experiences with networking tools [8]. The learning styles of students, as based on the Myers-Briggs personality type, can be used for the prediction of the level at which students and learners participate in e-learning. However, it should also be acknowledged that a critical related factor may be how familiar the student is with technologies. Several works of literature have indicated that experiences with computers strongly predicts the attitudes towards and the role that the internet and computers have on learning and teaching practices.

\section{How Social and Demographic Factors Affect e-Learning}

Some researchers have engaged in investigating the link that exists between social and demographic factors and the educational achievements of students. Other have highlighted how these factors affect the use of e-learning technologies but tutors and learners. Social and demographic factors include factors like the gender of students, learning styles, ethnicity, family size, family income levels, age, and marital status [9]. One main finding is that the learning style of a student does, indeed, affect their level of incorporation of e-learning materials into their learning practices. More conclusively, some personal factors that can affect the results that e-learning platforms have on learning include; the level of motivation, computer competency, communication capabilities and the learning style. Within Saudi Arabia, the female gender displays greater interests to obtain computer competency, as compared to the male gender, as e-learning technologies increase their access to learning and teaching resources that they would not have otherwise accessed through the traditional education system [5]. However, the main challenge faced by students is usually their own lack of autonomy or inability to learn by themselves or manage their own learning process.

\section{The Duration Spent on e-Learning Platforms}

Research has shown that the extent at which a student is engaged with e-learning has a positive correlation with the performance of students. The level of effort that student invests in e-learning practices, largely determine their examination performance. More studies within the sector have been conducted to examine what affects the duration that students spent on e-learning. This is usually dependent on the attitude of the student and how they perceive e-learning materials (as being useful or not useful), how easily they can be used as well as the delivery medium.
Students that spend longer durations of time on Internet-based learning, usually take on more responsibility for the learning process, which then increases their academic performance [10].

The capability of effectively managing learning time is a critical factor within the e-learning environment. This is because interactions with a web-based may need almost three more times that length of durations invested as compared to face-to-face teaching and learning practices. Students who find time management to be challenging may not really adopt e-learning into their learning practices or behavior [11]. Hence, the role that e-learning may have on the teaching or learning behaviors of students and teachers is largely affected by the perception of time management and competence that student may individually possess. Students that utilize their time effectively have a higher likelihood of performing better as compared to those who have not time management skills. Self-regulated learners are usually aware of effective time management due to their sensitivity to deadlines and the duration taken for the completion of each assignment [11]. They usually engage in the prioritization of learning tasks, with the evaluation of more complicated in comparison to less complex tasks in regards to the completion duration that is involved. There is an awareness of the need of evaluating how the study time is spent and the necessity of reprioritizing.

As mentioned before, differences in the learning styles of students also affect the level at which e-learning methods are able to enhance teaching and learning behaviors. This is due to the difference in how effective the channel of e-learning is for individual learners. Different learners have varying cognitive styles which have undergone extensive examinations. There is also great support within various works of literature with the statement that there are variations in the learning style of students.

\section{THEORETICAL AND CONCEPTUAL FRAMEWORKS}

E-learning has become a general synonymous term related to the academic world. Over the years, decision-makers have become more inclined to integrate e-learning into the educational system as it is cost-efficient and allows students to obtain better control of their process of learning as they can decide when, where and how to learn. The growth of e-learning has made a great transformation of ways in which information is handled and managed between instructors and their students. Based on this, several e-learning initiatives that have been formulated to help in the education of students and the utilization of electronic resources in several academic institutions. However, despite these initiatives, there have been several inadequacies in developing the provision and utilizing electronic resources in different academic institutions. There is still no effective comprehension of the impact that e-learning has had so far on the educational sector. There has been little to no effort recorded in identifying the influence and effects of e-learning on the academic performance of students in different learning institutions. With the widespread integration of e-learning in different levels of education, it has become significantly essential to examine the effects that this learning environment has on the 
behaviors of both instructors and students. Hence, this study will increase the level of information existent on the role of e-learning on academic performance.

Based on the reviewed literature, this present study will have great significance. First of all, the results that will be obtained will present a constructivist view of the role and position of e-learning in educational environments in regards to features such as the use of resources, and collaboration between the entities involved. This is key to act as a source of information for further research work within this particular area in the educational sector. Similarly, the study will also engage in the provision of knowledge and guidelines that can be used by policymakers. Hence, unlike other studies, the findings will not only highlight concepts of importance to the affected parties (the instructors and students) but will also hold importance for planners, and other social scientists. Research works are usually conducted with the perspective of the extension of the frontier of knowledge. In this light, the present study will contribute to the extension of the established frontier of knowledge which has been established by the literature review. This involves showing the predictive factors of highlighted features such as socio-demographic characteristics and prior computer skills.

\section{A. Theoretical Frameworks}

The focus of this study is the level of effect of e-learning technologies on various learning styles of students and how learners and students use it to gain knowledge in different ways, the facilitation theory and constructivist theory are well-known learning theories utilized to represent taxonomies of learning. The development of a collection certified process structured on the basis of learning theories which may help tutors in their encouragement of elevated preparation within students and provision of instructions in an online learning environment.

\section{B. Constructivism Theory}

Constructivism is a theory which is based on the belief that individuals create their own comprehension and information of the environment around them, through their experience of factors and reflection of these experiences [12]. When students come into contact with new concepts, there is usually a reconciliation with knowledge and experiences gained previously. This may change their beliefs or result in their abandonment of the new information. To act as active creators of knowledge, students should have the ability to ask questions, make explorations and assessments of the knowledge that they already have. Within classroom this theory means the encouragement of learners to utilize active techniques like experiments and the use of authentic data for the creation of knowledge and reflection of their own comprehension. Constructivism results in the modification of the role of the teachers so that the teacher assist a student in the construction of knowledge instead of merely reproducing facts [13]. The constructivist teacher engages in the provision of tools such as practices for the solution of problems and using inquiries to gain more information. This may include the use of e-learning materials for students to engage in forming and testing each idea, making conclusions, and the conveyance of this information with the other students around them. Teachers must comprehend the pre-existing conceptions that students may have and structure processes for addressing the information which can be used as a base. Constructivist tutors motivate their learners to take part in the assessment of how activities they get involved in assisting them in gaining comprehension. By formulating questions and directing them to themselves, learners can gain a range of expertise which involves the utilization of computers either offline or online. The learners then gain the capabilities needed to turn into self-motivated learners.

Teaching and learning practices in e-learning is seen as being self-directed learning, that further receives support from the constructivist approach. Based on the theory, e-learning is an active information procedure as generating information is conducted through personal experiences and interactions based on the environment that the learners exist in [2]. Based on this view, constructivism is distinguished from the objectivism, since learners are observed as passive recipients of information in objectivism.

Learning behaviors as associated with e-learning less effective as compared to the traditional educational practices on the basis of the objectivist educational philosophy. Learners are usually the leaders of self-regulated learning for developing total learning processes that includes perceiving problems, as well as adopting and assessing alternatives [14]. Learners have a similar role to that of producers through the organization and reorganization of knowledge like consumers, through the practical selection and using of knowledge. Students that have already been exposed to e-learning usually attend lessons for the registry of the times, places, subjects as well as the alteration of the lessons being attended. Proper evaluation of learners is usually more challenging as compared to traditional systems of education already being utilized, as the progressive learning method of evaluating learners is changed and also since personal interactions with the teachers (which are critical) are not conducted. Hence, the management of one's capability of organizing self-learning durations, processing of data, planning, and management of knowledge is critical.

\section{Facilitation Theory (The Humanist Approach)}

This theory was created by Carl Rogers. One core base of this theory is that learning occurs since the human being is naturally eager to learn and have responsibility for and at the core of learning practices. Hence, learning is approached as person-centered. E-learning only occurs if the individuals involved sign up and have the self-drive and eagerness to engage in learning despite where they are located in regards to learning institutions. Teachers mainly act as facilitators. The level of effort provided by the teacher is not a guarantee of success unless learners desire to learn. Within the theory, learning is usually observed as involving a change in one's perception which may involve the discovery of an individual's strengths and deficiencies [15]. Students engaged in e-learning have to have a perception that it is possible to acquire knowledge through the e-learning system. A positive level of self-perception has a consolidating effect on learning by allowing the learners to attack the target skills confidently. Learners are seen as being able to obtain information on their own, which negates the role that 
transmission of information and the underestimating of the contribution of teaching.

\section{Conceptual Framework}

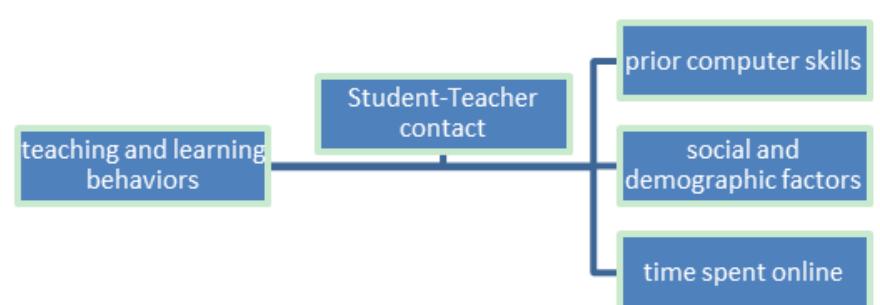

Moderating Variable Dependent Variable Independent Variables Fig. 1. Conceptual framework.

The conceptual framework above was utilized in the research. The independent variables include; computer competence, social and demographic factors, and the amount of time that students and teachers spend online that may affect the teaching and learning behaviors. Computer skills before any interaction with e-learning technologies are seen to increase the ease for learner to utilize computers and computer software which are utilized for the delivery of academic; social and demographic factors with the inclusion of aspects such as gender which have a role in learning and teaching behaviors. The learning and teaching behaviors of students and teachers are the dependent variable, how do these behaviors change the basis of the independent variables. The contact between teachers and students is the moderating variable which provides the effect of the relationship where it conducts the moderation of the relationship between the independent variables. Teaching and learning behaviors within an e-learning setup can be affected by several variables, in a positive or a negative way.

\section{RESEARCH METHODS}

\section{A. Research Design}

The research design used was an analytical survey. These also refer to diagnostic studies which try to make the explanation as to why some situations exist. The findings also enabled the researcher to make an examination of the links that exist between the variables and how explanatory inferences can be drawn. Within this study, the researcher was focused on the establishment between the use of e-learning materials and the teaching and learning behaviors within the Saudi education system.

\section{B. Units of Analysis}

Units of analysis are those structured for the aggregation of their characteristics for the description of an abstract phenomenon. They can also be described as what is under analysis. The unit of analysis within this paper was the study modes (e-learning and conventional learning)

\section{Study Population}

In this study, the population of interest was the students and teachers in the urban sections of Saudi Arabia who have access to computers for e-learning purposes. The target population for the study was 200 participants in total. This sample size was seen as appropriate as most of the participants involves were located in different towns and areas across the country, constraints such as time did to enable the inclusion of a larger number of participants. For equal representation, a hundred participants involved in entirely traditional learning and teaching behaviors were involved.

\section{Sampling Methods}

A systematic random sampling process was used as a neutral start point was acknowledged by the researcher and the first student is chosen randomly from the target location. The consideration of gender equality was also essential and hence, for each male student picked, a female student was also picked. For the identification of students with access to e-learning resources, a list of schools was obtained from then obtained from the education ministry, after which systematic random sampling was utilized for the selection of one hundred students and one hundred teachers.

\section{E. Data Collection Instruments}

The main instrument used for collecting data within the study was questionnaires. The questions within the questionnaires were structured (close-ended) and unstructured (open-ended). The structured questions were created for measuring subjective responses for the clarification of the objective responses while also enhancing the formulation of recommendations. There were two separate questionnaires designed- one specifically for the teachers and the other one was used to address the characteristics of the students.

\section{F. Reliability}

Reliability refers to the level at which a research instrument would obtain similar results after being used repeatedly. To ensure reliability, the issuance of the questionnaires to the respondents was conducted by the researcher who also carried out their collection. After two weeks, the questionnaires underwent testing by being administered for the second time to respondents that had similar characteristics. This enables the internal consistency of the questionnaire while also affirming responses from the selected sample.

\section{G. Validity}

Validity is the establishment of a link between the data and variables of interest. To ensure that the data collected was accurate, the researcher conducted a pre-testing of the questionnaires while also analyzing the results and making corrections on the questions that did not have clarity. The researcher also paid a visit to the students under the sampling population to ensure that they had an understanding of the importance of the study.

\section{H. The Analysis of Data and Report}

Data analysis is an iterative process which is made up of data reduction, it display, and drawing of conclusions. Within this research, data reduction occurred from critical elements in implementing e-learning to the enhancement of teaching and learning behaviors. It is then displayed in an organized form. 


\section{Ethical Issues}

Confidentiality was an issue within the study. However, for its maintenance, the participants involved were guaranteed that any identifying data included would not be made available to other individuals who were not part of the study. The researcher also sought permission to conduct the research from the students themselves. Informed consent was obtained from the participants concerning the procedures that were involved. Lastly, anonymity was maintained concerning the identities of participants for guaranteeing privacy.

\section{FINDINGS}

\section{A. Questionnaire Return Rate}

The study response rate was $75 \%$ as shown in table 1.0 below. A larger percentage of the completely filled questionnaires were from the students under the conventional study made, only $35 \%$ of the questionnaires that were completely filled were by students that incorporated e-learning.

\begin{tabular}{|l|l|l|}
\hline \multicolumn{2}{|c}{ TABLE I: THE RESPONSE RATE } \\
\hline & Frequency & Percent $(\%)$ \\
\hline $\begin{array}{l}\text { Students that incorporate } \\
\text { e-learning }\end{array}$ & 25 & 12.5 \\
\hline $\begin{array}{l}\text { Students that incorporate } \\
\text { traditional mode }\end{array}$ & 60 & 30.0 \\
\hline $\begin{array}{l}\text { Teachers that incorporate } \\
\text { e-learning }\end{array}$ & 28 & 14.0 \\
\hline $\begin{array}{l}\text { Teachers that incorporate } \\
\text { traditional mode }\end{array}$ & 47 & 23.5 \\
\hline $\begin{array}{l}\text { Invalid } \\
\text { Total }\end{array}$ & 50 & 25.0 \\
\hline
\end{tabular}

\section{B. Socio-demographic Factors}

This is a presentation of the socio-demographic data of the respondents the analysis was reliant on this information of the respondents for the categorizing of different outcomes.

\section{1) Gender}

The study sought to establish the distribution by gender of the participants in selecting the sample. It was observed that $42 \%$ of the respondents were male while $58 \%$ of the participants were female. This was an indication that more females to males were reliant on e-learning materials for the enhancement of teaching and learning behaviors.

\section{2) Student Average Scores}

The study wanted to establish the average score of the students. The figure below represents the performance of students who use e-learning methods as compared to those who are engaged in entirely traditional learning and teaching behaviors. In the participants who scored A, 55 percent by those who combined conventional study mode and e-learning strategies while $45 \%$ under a completely conventional teaching and study mode. $62 \%$ and $38 \%$ of the students who scored B were on e-learning and conventional study modes respectively.

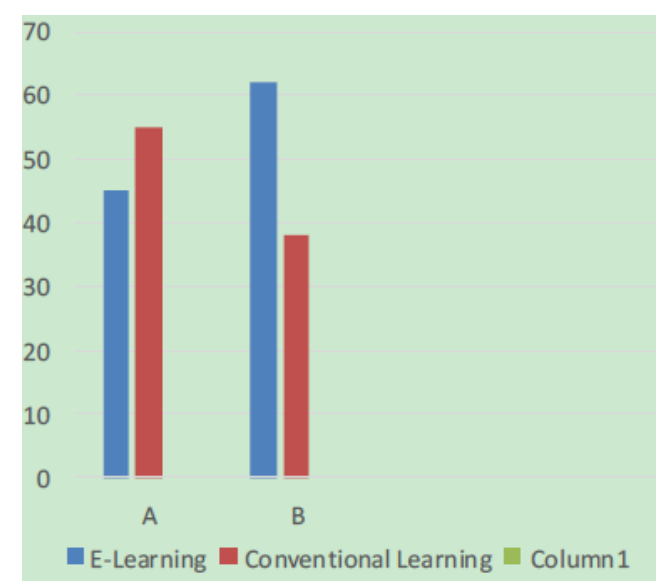

Fig. 2. Student average scores.

\section{3) Online Study Hours}

The study sought to establish the number of hours that students spend in their online study. $15 \%$ of the population studied for 1-2 hours, while $40 \%$ of the population studies online between 3-5 hours, and 35\% were between 5-9 hours. The study also showed that female participants studying and teaching using e-learning practices as compared to the male gender.

4) The Impact of Study hours on Teaching and Learning Behaviors

The study was focused on establishing the effect of study hours in a day on the teaching and learning behaviors. The figure below showed that those who spend between 1-2 hours made about $17 \%, 18 \%$, and $18 \%$ of the students who scored A's, B's and C's respectively.

\section{Impact of Computer Competency on Teaching and Learning Behaviors}

This is a representation of the level of anxiety that students and teachers have as related to computers and how they academically perform and their efficiency of tutors while teaching. $12 \%$ of the respondents admitted to being anxious when utilizing computers while $86 \%$ of the respondents stated that they did not have any anxiety. $100 \%$ of the students who scored A in their studies stated that they did not have anxiety when using computers for learning practices, while $80 \%$ of those who scored B also stated that they did not have any anxiety.

\section{Summary of Findings}

A majority of the respondents within the study were female, which showed that more females as compared to male were interested in the use of e-learning materials within the educational environment. Students who used the conventional learning mode had higher performance in compared to those who used e-learning as of the students who scored A's 55\% used the conventional study mode, while $45 \%$ incorporated e-learning into their studying and learning practices. On the other hand, a majority of those who scored B incorporated e-learning practices into their education (62\%), while $38 \%$ only used conventional studying habits. Also, the length of duration taken upon studying using e-learning practices had an effect on how effective teaching and learning behaviors were- as compared to the academic performance and control over grades.

E-learning in Saudi Arabia has effectively transformed the 
educational systems at different levels, resulting in the improvement of the learning experiences of students that are involved. Most students within the country, as based on the study's findings, have access to personal computers. However, despite this access, only a small percentage is actually interested in e-learning. As based on the Saudi Arabian Ministry of Higher Education's vision there is an increased realization of the potential of the educational tool and modern pedagogy methods (such as the incorporation of e-learning) to the education process [1]. This means that e-learning has already been observed as having great significance in education. Also, students who have positively responded to the use of e-learning materials that they have access to, have displayed increased confidence within their learning capabilities, which is shown in part by their better academic performance. E-learning materials provide a wide range of opportunities that tutors can take advantage of to introduce new information to their students. It improves the quality of the learning experience while extending the reach that any concerned teacher or tutor may have. By removing barriers to achievement, e-learning presents new and creative ways that teachers can utilize for the motivation and engagement of their students despite their capabilities by offering differentiated learning, differentiated learning is particularly useful for the students that need extra support in areas such as literacy, numeracy, and ICT [16].

Through these materials, learners of all types within the Saudi community can access individualized learning, with the inclusion of those that are disadvantaged, disabled or have special learning needs. This is enhanced further by personalized learning support through information, advice, and guidance services. It assists to find the course they require, with seamless transitions to the next stages of learning.

\section{DISCUSSION}

The internet acts as a technological development that has the potential to change, not only the retention of society and accessing knowledge but also transforming and restructuring traditional models. The use of the internet for the delivery of e-learning initiatives has structured expectations within the business sector and the education sector as well. E-learning has enables learners and teachers to take part in the expansion of their existing geographical reach, capitalizing new prospective students, and to make an establishment of themselves as global education providers. E-learning has achieved prominence for future development in different levels of education, and yet little common understanding exists. Liaw et al [2] make an outline of the wide spectrum of interests and comprehensions which are linked to the term, based on a social constructivist approach, whose objective is to make utilization of the communicative potential of online learning. There are also many variances in regards to students that take up e-learning as concerning their age or motivation, and the discipline that they study.

Based on the constructivist theory, online media can be utilized for supporting distributed collaborative interaction and dialogue, while also increasing access to information-rich sources. These courses place significance on comprehension, instead of the memorizing and reproduction of facts, and contributions of social interactions and collaborations to learning [4]. Hence, with an application of constructivist theory, there are several pedagogies to be understood for the optimization of the potential of networked environments. These include collaborative e-learning, activity-based learning, resource-based learning, and problem-based learning. These pedagogies are essential as their operations involve the provision of opportunities for students to learn by engaging in activities, which may involve collaborative work, the solution of problems, and open access to electronic sources.

These pedagogies seem more applied to the female gender as opposed to the male gender. Within the findings, there is an indication that females have a greater reliance on e-learning materials as a way to enhance their teaching and learning behaviors. Based on the existing pedagogies, a combination of conventional study mode and e-learning strategies enhances collaborations and the basis of activities. This, in turn, supports the transformation of the educational system as the learning experience of students is improved. Resource-based and problem-based learning create a large number of opportunities that tutors can take advantage of for the introduction of new information to their students. Tutors can extend their reach to their students by utilizing the new and creative ways available for motivating and engaging their students. This is because of the existence of differentiated learning which ensures that all students, despite their learning needs, are exposed to individualized educational experiences.

As it is delivered through technology-based solutions, e-learning makes elimination of the expense and inconvenience of getting the instructors and students within the same place. It also increases just-in-time access to timely information. E-learning allows instructors to constantly and consistently engage in the updates of lessons and materials within the general network instantly. This ensures that the quality of the content and related educational materials are enhanced and students can immediately access the most current data. There can be the retrieval of information just before it is required, instead of being learned once in a classroom and then be forgotten. Hence, for learners, e-learning portals increase the consistency of learning and their ability to constantly access data and information [14]. In turn, there is increased retention of content by enabling the personalization of learning. This is by creating a platform that supports a wide range of individuals differences in learning styles.

Through e-learning, learners are exposed to an elevated level of simulation which can be personalized to the proficiency of each learner. With daily access, learners can learn at their own pace and make reviews of learning material as often as they need to. Since they can engage in customizing the learning material to suit their needs, students can gain a greater level of control over their learning process, and gain a better comprehension of the material [14]. This largely speeds up the learning curve in comparison to entire dependence on instructor-led training. This infinitely increases the value of education that the learners receive.

Based on the constructivism theory, individuals create their comprehension and information about the environment 
around them. E-learning portals and tools create more room for increased collaboration and interactions of students with experts and peers. Teachers are also able to use a wide range of teaching and communication techniques such as case studies, story-telling, streamed videos, discussion group and bulletin boards for the creation of an interactive online environment. This makes the education environment more stimulating while encouraging critical reasoning as it enables an interaction that is similar to a small group setting. Students that utilize e-learning platforms for learning are usually drawn into the subject matter at a deeper level due to the discussions that they get involved in. this is further supported by the fact that there is no monopolizing of attention within an online environment [15].

Due to the existing dependence of the current generation of learners on technology and social media platforms, using an e-learning platform enables increased peer contact which then elevates their performance. Lastly, e-learning acts as a risk-free learning environment. Students are more likely to try new things and explore new learning fields as there is no risk that they will expose themselves. Students are not only able to understand the reasons why they fail but also have an opportunity to try again. This type of learning experience engages the elimination of the embarrassment of failure in front of other peers. Students and instructors can engage in successful learning and teaching behaviors such as proactive participation, provision of feedback for the improvement of future experiences, and communication of learning possibilities. Students can become more active within their educational programs and services while also improving their skills and competencies in digital technologies.

\section{CONCLUSIONS AND RECOMMENDATIONS}

\section{A. Conclusion}

Knowledge utilization in the education environment is one of the main factors that should be taken into consideration. As a major tool for the utilization of knowledge, the incorporation of e-learning can be useful in capitalizing the resources the teacher has while increasing the quality of education that students are exposed to. The benefits and role of e-learning to education is significant for all the parties involved. Students are able to easily access the educational resources without having to travel or taking excessive time to search for these resources while teachers gain new channels of teaching and providing knowledge to their students.

The study makes an assessment of the effect of electronic learning on teaching and learning behaviors of students and teachers within the Saudi academic environment. A large number of students are not well prepared to carry out their studying and teaching practices using e-learning strategies, due to the unexpected complexities of how IT is applied as a learning tool which needs commitment as there are no strict regulations surrounding the exact learning durations [14]. The world has become smaller, and great progress has been made in the sectors of information and communication technologies. IT can be accessed by many students and teachers across the country, especially due to several initiatives by the Ministry of Education such as the availing of the National Education Portal (iEN). This has increased the independence of the individuals that are involved in the education sector while increasing mobility by reducing the distance and difficulty of communication between students and teachers. The analysis gathered on the small sample of two hundred people, has shown that, there are still several issues that have to undergo critical consideration before e-learning can be clearly stated as being a great contribution to the enhancement of the performance of students and the practices of the teachers at each level of the education system, despite the individual difference that may exist due to personal backgrounds and learning environments. There are still large strides to be made before the Saudi government can fully incorporate IT into the education system and for the benefits of e-learning to be observed through the performance of the individuals that are involved.

\section{B. Recommendations}

This research provided its own point of view as well as the examinations of different views concerning the role that e-learning materials have on the enhancement of learning and teaching behaviors. Despite the discovery that several issues have not been effectively addressed to E-learning implementation procedures, as the main focus on the research was on prior computer skills, the number of hours individuals spends on e-learning materials and the social and demographic factors. The following are the recommendations;

1) Critical aspects such as institutional factors, management factors, pedagogical issues, technological issues, interface design issues, evaluation issues, and resource support issues. The impact of e-learning materials with respect to these issues should be critically investigated.

2) A need also exists for carrying out detailed research including case studies on the basis of survey questionnaires with the involvement of different learning institutions which will, in the end, provide an enhanced comprehension of the effect of learning factors within the implementation procedures.

\section{CONFLICT OF INTEREST}

The author declares that there is no conflict of interest regarding the publication of this paper.

\section{AUTHOR CONTRIBUTIONS}

This paper had been written by a single author who had done all the research, writing and review stages. The author approved the final version of this paper.

\section{REFERENCES}

[1] A. M. Al-Asmari and M. S. R. Khan, "E-learning in Saudi Arabia: Past, present and future," Near and Middle Eastern Journal of Research in Education, p. 2, 2014.

[2] S. S. Liaw and H. M. Huang, "Perceived satisfaction, perceived usefulness and interactive learning environments as predictors to self-regulation in e-learning environments," Computers \& Education, vol. 60, no. 1, pp. 14-24, 2013.

[3] V. Arkorful and N. Abaidoo, "The role of e-learning, advantages and disadvantages of its adoption in higher education," International 
Journal of Instructional Technology and Distance Learning, vol. 12, no. 1, pp. 29-42, 2015.

[4] F. A. Rowe and J. A. Rafferty, "Instructional design interventions for supporting self-regulated learning: Enhancing academic outcomes in postsecondary e-learning environments," Journal of Online Learning and Teaching, vol. 9, no. 4, pp. 590-601, 2013.

[5] L. A. Alfarani, "November. Influences on the adoption of mobile learning in Saudi women teachers in higher education," in Proc. 2014 International Conference on Interactive Mobile Communication Technologies and Learning (IMCL2014), pp. 30-34, IEEE, 2014,

[6] M. Crommelinck and F. Anseel, "Understanding and encouraging feedback-seeking behaviour: A literature review," Medical Education, vol. 47, no. 3, pp. 232-241, 2013.

[7] O. Owino, "The impact of e-learning on academic performance: A case study of group learning sets," Masters Project, University of Nairobi, 2013.

[8] S. R. Harandi, "Effects of e-learning on students' motivation," Procedia-Social and Behavioral Sciences, vol. 181, pp. 423-430, 2015.

[9] R. Mbarek and F. Zaddem, "The examination of factors affecting e-learning effectiveness," International Journal of Innovation and Applied Studies, vol. 2, no. 4, pp. 423-435, 2013.

[10] A. N. Islam, "Investigating e-learning system usage outcomes in the university context," Computers \& Education, vol. 69, pp. 387-399, 2013.

[11] C. H. Chung, L. A. Pasquini, and C. E. Koh, "Web-based learning management system considerations for higher education," Learning and Performance Quarterly, vol. 1, no. 4, pp. 24-37, 2013.

[12] S. O. Bada and S. Olusegun, "Constructivism learning theory: A paradigm for teaching and learning," Journal of Research \& Method in Education, vol. 5, no. 6, pp. 66-70, 2015.

[13] T. M. Duffy and D. H. Jonassen, Constructivism and the Technology of Instruction: A Conversation, Routledge, 2013.
[14] J. Broadbent and W. L. Poon, "Self-regulated learning strategies \& academic achievement in online higher education learning environments: A systematic review," The Internet and Higher Education, vol. 27, pp. 1-13, 2015.

[15] L. Nelson, C. J. Cushion, P. Potrac, and R. Groom, "Carl rogers, learning and educational practice: Critical considerations and applications in sports coaching," Sport, Education and Society, vol. 19, no. 5, pp. 513-531, 2014

[16] N. Songkram, J. Khlaisang, B. Puthaseranee, and M. Likhitdamrongkiat, "E-learning system to enhance cognitive skills for learners in higher education," Procedia-Social and Behavioral Sciences, vol. 174, pp. 667-673, 2015.

Copyright $\odot 2020$ by the authors. This is an open access article distributed under the Creative Commons Attribution License which permits unrestricted use, distribution, and reproduction in any medium, provided the original work is properly cited (CC BY 4.0).

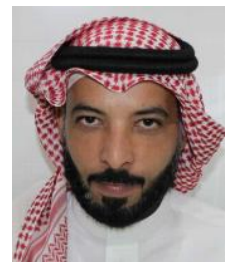

Abdullah Alenezi is assistant professor in the Educational Technology Department, Faculty of Education, Northern Borders University, Saudi Arabia. His major areas of interest and expertise are: organizational change, teaching and learning outcomes arising from uses of leading-edge technologies, implementation and management of leading-edge technologies at the local authority and individual institution levels, uses and impacts of technologies and technology-based resources in formal educational environments, distance learning and training, and technology integration in the Saudi context. 